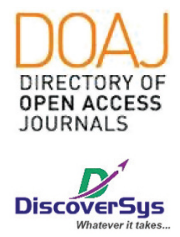

Published by DiscoverSys

\section{Laparoscopic pyelolithotomy in treating extra-renal pelvic calculi at Sanglah General Hospital: a case series}

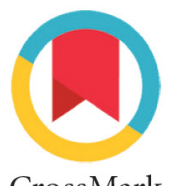

CrossMark

\author{
Made Kurniawan $\mathrm{AS}^{1 *}$, Kadek Budi Santosa²
}

\section{ABSTRACT}

Background: This study aims to describe our initial experience in treating extra-renal pelvic calculi using retroperitoneal laparoscopic pyelolithotomy techniques in Urology Division, Department of Surgery, Sanglah hospital, Bali.

Case Description: There were seven patients enrolled with extrarenal pelvic calculi in this study whereas two of them accompanied by calyx inferior secondary stones. All the patients underwent retroperitoneal laparoscopic pyelolithotomy with DJ Stent applied. The operating time was improving in each procedure, with average time was 110 minutes, VAS at the first day post-operative was 1-2, a drain was removed on the second day, one of them was extended until the sixth day, most patients was discharged on postoperative day 3. All patients were stented for 3 to 4 weeks; The stents were removed with office cystoscopy. All patients were stone free on follow-up imaging.

Conclusion: Retroperitoneal laparoscopic pyelolithotomy is a safe alternative for the management of pelvic renal calculi with minimal post-operative pain and shorter length of stay.

Keywords: Retroperitoneal laparoscopic, pyelolithotomy, extra-renal pelvic calculi

Cite This Article: A.S.M.K., Santosa, K.B. 2019. Laparoscopic pyelolithotomy in treating extra-renal pelvic calculi at Sanglah General Hospital: a case series. Intisari Sains Medis 10 (1): 209-213. D0l: 10.1556/ism.v10i1.339

${ }^{1}$ General Surgery Resident/ Department of Surgery, School of Medicine, Udayana University/ Sanglah General Hospital, Bali, Indonesia

${ }^{2}$ Division of Urology Department of Surgery, School of Medicine, Udayana University/ Sanglah General Hospital, Bali, Indonesia

*Corresponding:

Made Kurniawan AS; Division of Urology Department of Surgery, School of Medicine, Udayana University/Sanglah General Hospital;

kurniaone01@yahoo.com
Received: 2018-10-31

Accepted: 2019-03-29

Published: 2019-04-01

\section{BACKGROUND}

With the advances in shock waves lithotripsy (SWL) and endourological procedures, such as percutaneous nephrolithotomy (PNL) and ureterorenoscopy (URS), the treatment of urinary stone disease has changed markedly. The indications for open surgery to treat renal calculi are limited based on prior study.1,2 According to the guidelines, laparoscopic pyelolithotomy (LPL) is indicated when endoscopic procedures fail, if there is a complex stone burden, renal and anatomical abnormalities, or if there are indications for open surgery. ${ }^{2-9}$ We reported 7 patients with extrarenal pelvic stone underwent Retroperitoneal Laparoscopic pyelolithotomy. Extrarenal pelvic stone is a stone in the renal calyx and pelvis which is located outside the renal parenchyma. ${ }^{10}$ This study aims to elaborate their complication, visual analog scale (VAS), additional procedures, and length of stay after this procedure as a preliminary study among case series

\section{CASE DESCRIPTION}

The study period extends from November 2015 until September 2016. Seven patients underwent retroperitoneal laparoscopic pyelolithotomy with DJ Stent applied. Patient 1 was a 58-years-old woman with mild flank pain on the left side without radiating to the groin, with history of hematuria since 3 months, Ultrasound and X-Ray KUB showed extra-renal pelvic calculi on left side, $\varnothing 3,1 \mathrm{~cm}$ with hydronephrosis grade II [S], Retroperitoneal laparoscopic pyelolithotomy with DJ stent [S] was done. Three weeks later the stent was removed with office cystoscopy.

Patient 2 was a 75-years-old man with mild flank pain on the right side without radiating to the groin, with hematuria for 1 month. Ultrasound and X-Ray KUB showed extra-renal pelvic calculi on right side, $\varnothing 3,5 \mathrm{~cm}$ and calyx inferior secondary stones with hydronephrosis grade II (D), Retroperitoneal laparoscopic pyelolithotomy (D) and spoiling procedure via ureter using Nasogastric tube fr. 8 to eliminate stones on calyx inferior and then DJ stent (D) applied, Three weeks later,the stent was removed with office cystoscopy.

Patient 3 was a 59-years -old woman with hematuria since 1 week and history of mild flank pain since 4 months, Ultrasound and X-Ray KUB showed extra-renal pelvic calculi on right side, $\varnothing 2,8 \mathrm{~cm}$ with hydronephrosis grade II (D). 
Retroperitoneal laparoscopic pyelolithotomy with DJ stent (D) was done. Three weeks later, the stent removed with office cystoscopy.

Patient 4 was a 70 -years-old woman presented moderate flank pain on the left side without radiating to the groin for 7 days with hematuria for 3 days, history of mild flank pain for 2 months. Ultrasound and X-Ray KUB revealed extra-renal pelvic calculi on left side $\varnothing 3,2 \mathrm{~cm}$ and hydronephrosis grade II [S]. Retroperitoneal laparoscopic pyelolithotomy with DJ stent $[S]$ was done. Four weeks later, the stent removed with office cystoscopy.

Patient 5 was a 47-years-old woman with moderate flank pain on the right side without radiating to the groin for 3 months and become worse by the time. She also had a history of hematuria. Ultrasound and X-Ray KOB showed extra-renal pelvic calculi on right side accompany with calyx inferior secondary stones and hydronephrosis grade II (D). Retroperitoneal laparoscopic pyelolithotomy (D) and spoiling

Table 1. The summary of several cases included in this study

\begin{tabular}{cccll}
\hline No & Gender & Age & \multicolumn{1}{c}{ Diagnose } & \multicolumn{1}{c}{ Procedure } \\
\hline 1 & Female & 58 & $\begin{array}{l}\text { extra-renal pelvic calculi } \\
\text { [S] with, hydronephrosis } \\
\text { grade II [S] }\end{array}$ & $\begin{array}{l}\text { Retroperitoneal laparoscopic } \\
\text { pyelolithotomy with DJ stent } \\
{[\mathrm{S}]}\end{array}$ \\
& Male & 75 & $\begin{array}{l}\text { extra-renal pelvic calculi } \\
\text { (D), calyx inferior } \\
\text { secondary stones with } \\
\text { hydronephrosis grade } \\
\text { II (D) }\end{array}$ & $\begin{array}{l}\text { Retroperitoneal laparoscopic } \\
\text { pyelolithotomy (D) and } \\
\text { spoiling procedure via ureter } \\
\text { using Nasogastric tube fr } 8 \\
\text { to eliminate stones on calyx } \\
\text { inferior and then DJ stent (D) } \\
\text { applied }\end{array}$
\end{tabular}

$3 \quad$ Female 59 extra-renal pelvic calculi (D), hydronephrosis grade II (D

$4 \quad$ Female $\quad 70 \quad$ extra-renal pelvic calculi[S], hydronephrosis grade II $[S$

$5 \quad$ Female 47 extra-renal pelvic calculi(D), with calyx inferior secondary stones, hydronephrosis grade II (D)

$6 \quad$ Male 38 extra-renal pelvic calculi (D), hydronephrosis grade II (D

Retroperitoneal laparoscopic pyelolithotomy with DJ stent (D)

Retroperitoneal laparoscopic pyelolithotomy- with DJ stent [S]

Retroperitoneal laparoscopic pyelolithotomy (D) and spoiling procedure via ureter using Nasogastric tube fr 8 to eliminate stones on calyx inferior and then DJ stent (D) applied

Retroperitoneal laparoscopic pyelolithotomy with DJ stent (D)

$7 \quad$ Male $\quad 38 \quad$ Extra-renal pelvic calculi [S], hydronephrosis grade IV [S] procedure via ureter using Nasogastric tube fr 8 to eliminate stones on calyx inferior and then DJ stent (D) applied. Four weeks later,the stent was removed with office cystoscopy.

Patient 6 was a 38-years-old man presented with hematuria since 2 weeks and history of mild flank pain since 5 months, Ultrasound and X-Ray KUB showed extra-renal pelvic calculi on right side, $\varnothing 3 \mathrm{~cm}$ with hydronephrosis grade II (D). Retroperitoneal laparoscopic pyelolithotomy with DJ stent (D) was done. Three weeks later, the stent removed with office cystoscopy.

Patient 7 was a 38-years-old man presented with hematuria since a week and history of moderate flank pain since 3 months, Ultrasound and X-Ray KUB showed extra-renal pelvic calculi on left side, $\varnothing 4 \mathrm{~cm}$ with hydronephrosis grade IV [S]. Retroperitoneal laparoscopic pyelolithotomy with DJ stent [D] was done. Four weeks later, the stent removed with office cystoscopy.

Upon admission, a detailed history was obtained from each patient. A general physical examination was performed. The general examination was followed by a systemic examination, recognition of any co-morbid illnesses. Each patient and his/ her attendants were fully informed about the natures of both laparoscopic and open surgery and their associated complications, and written consent was obtained from the patient before surgery. Investigations performed include routine investigations, such as the complete blood count, faal hemostatic, urine examination, kidney function tests, serum electrolytes, ECG (electrocardiogram), chest X-rays. Imaging studies examining the urinary tract included ultrasonography and X-ray KUB. Prophylactic antibiotic (injection Cefazoline 2 grams IV given an hour before intubation) were administered in all cases (Figure 1).

The patient was initially in the supine position. This was to allow for intravenous access, the induction of general anesthesia, endotracheal intubation, and bladder catheterization. Lather, the patient was moved into a right or left the lateral position, depending on the side of the patient on which the operation was performed. The foot end of the table was lowered. A $1,5 \mathrm{~cm}$ incision was made below the tip of the $12^{\text {th }}$ rib along the midaxillary line, which served as the location for the middle trocar and was primarily used for the camera port. A hole was created from the skin to the muscle into the retroperitoneal space using a blunt hemostat. The full working space was then created with a balloon dissector. The balloon was inflated with $500-600 \mathrm{~mL}$ of air and kept in place for a minimum of 5 minutes to achieve hemostasis. After the removal of the balloon, 2 working ports 

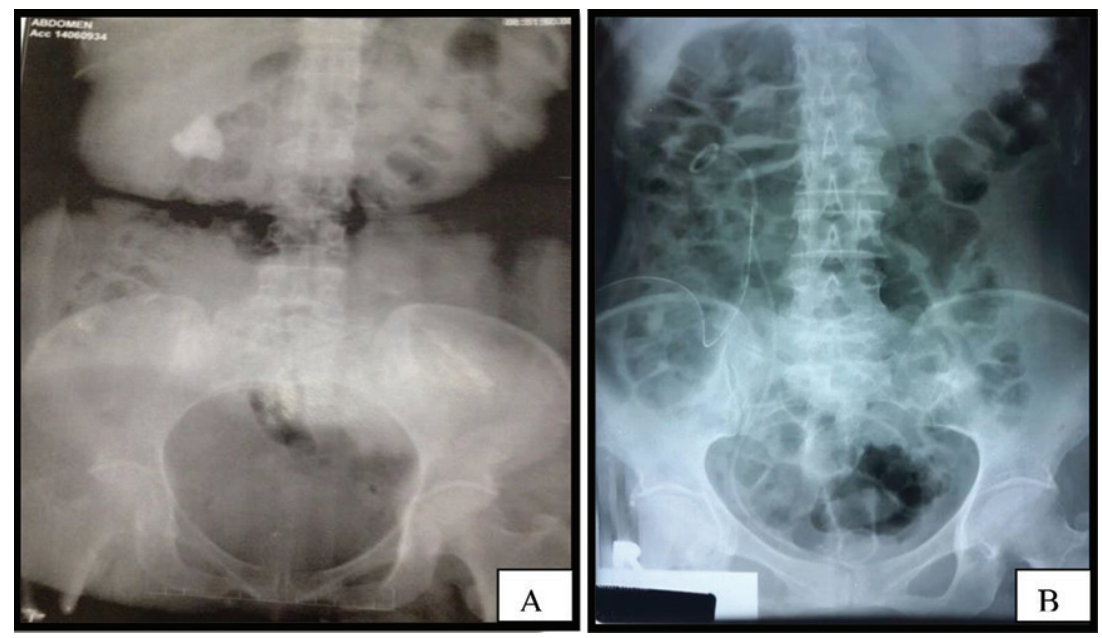

Figure 1. X-Ray KUB before (A) and following (B) procedure

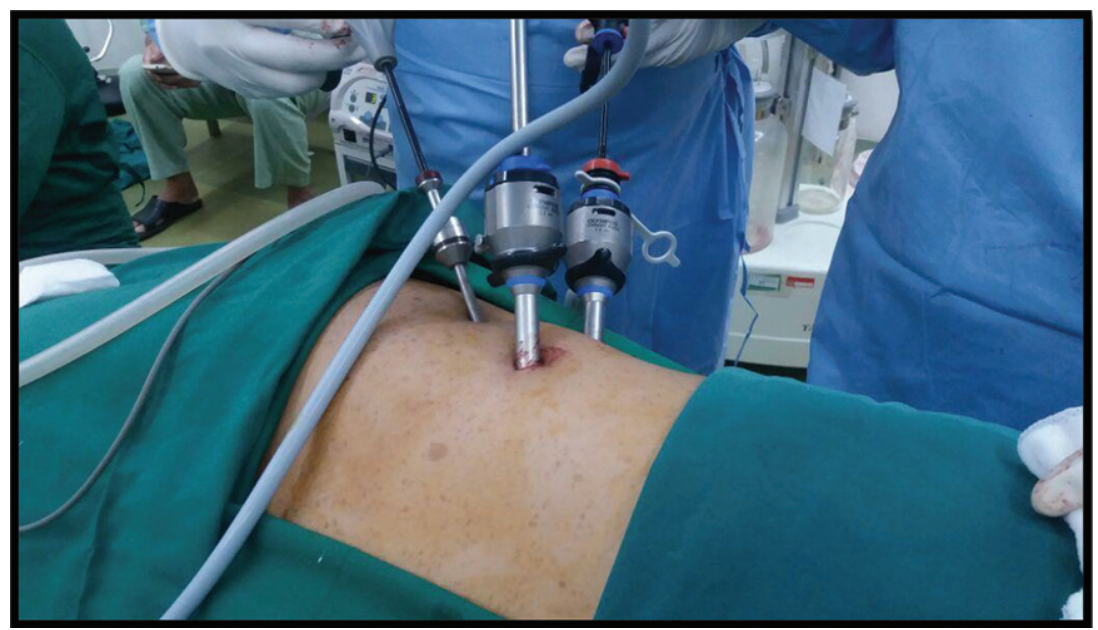

Figure 2. Trochar position in the supine position

with $10 \mathrm{~mm}$ length were placed parallel to the first trocar at the level midclavicular line, and $5 \mathrm{~mm}$ was placed at supra-iliac crest. Finally, a Hasson's cannula was secured at the primary port site, and a 30-degree telescope was advanced. The $\mathrm{CO} 2$ inflation was performed through one of the ports, and the retro pneumo peritoneum was created. In the retroperitoneal space, the ureter was identified by its peristaltic characteristics and the arborization of its vessels anterior to the psoas muscle. It was traced up to the ureteropelvic junction. Accuracy was taken care to avoid any injury on the lower polar vessels. The pelvis was carefully mobilized. In general case, another port place medial to third port to help mobilized fatty tissue covering the field of surgery. Pyelolithotomy was performed using an end of knife or endo-scissors. The stone removed with a right angle dissector. A preplaced double -J stent was advanced over the guide antegrade manner. The pyelolithotomy was then closed with interrupted 4-0 Vicryl sutures.The stones were removed using handschoen bag. A drain was placed through the most dependent port, followed by the relaxation of the retro pneumo peritoneum, the removal of the trocars and the closure of the port sites (Figure 2 and 3 ),

All procedures were carried out without the need for conversion to open surgery. Mean operative time was 110 minutes (range 90-150), Mean estimated blood loss was $40 \mathrm{~mL}$ (range 3050 ), two patients need to have spoeling procedure using Nasogastric tube fr.8 to eliminate their calyx inferior secondary stones, drain was removed 2 days after operation,length of stay was 3 days, no major complication found postoperatively. The outcome characteristic are summarized in Table 2.

\section{DISCUSSION}

Renal calculi were the most commonly managed with SWL, PNL or URS. Patients with large stones in ectopic kidneys presented challenging dilemmas when using these modalities. ${ }^{1}$ Whereas an open surgery has traditionally been the alternative when these measures fail, success with minimally invasive techniques is possible. Laparoscopic pyelolithotomy can be an appropriate option in certain cases. Laparoscopic surgery presents many advantages over open surgery to the patients with a lesser degree of pain and hemorrhage, shorter hospital stay, and better cosmetic outcomes while providing a better view and safer procedure to the surgeons. ${ }^{10-11}$ Laparoscopic interventions were applied as transperitoneal and retroperitoneal approaches. The most important factor in choosing between these two approaches is the experience and preference of the surgeon. However, both methods have their ups and downs. Transperitoneal approach provides a better range of movement due to the larger surgical site and higher distances between the ports. However, in order to reach the retroperitoneal located kidney via a transperitoneal approach, the mobilization of intraabdominal organs is required. In retroperitoneal approach, in addition to the difficulty of controlling renal hilus, it is hard to reach the upper pole of kidney and the distal ureter, while there is a need to learn to work in this area. However, it also presents some advantages such as faster kidney reach, an absence of shorter hospital stay, and easy-to-apply nature in patients with a history of abdominal surgery. ${ }^{10}$ Our initial experience on seven patients with extra-renal pelvis stone showed that retroperitoneal laparoscopic pyelolithotomy minimally invasive with a lesser degree of pain and hemorrhage, shorter hospital stay, and better cosmetic outcomes. Different laparoscopic approaches to these patients have been reported. 


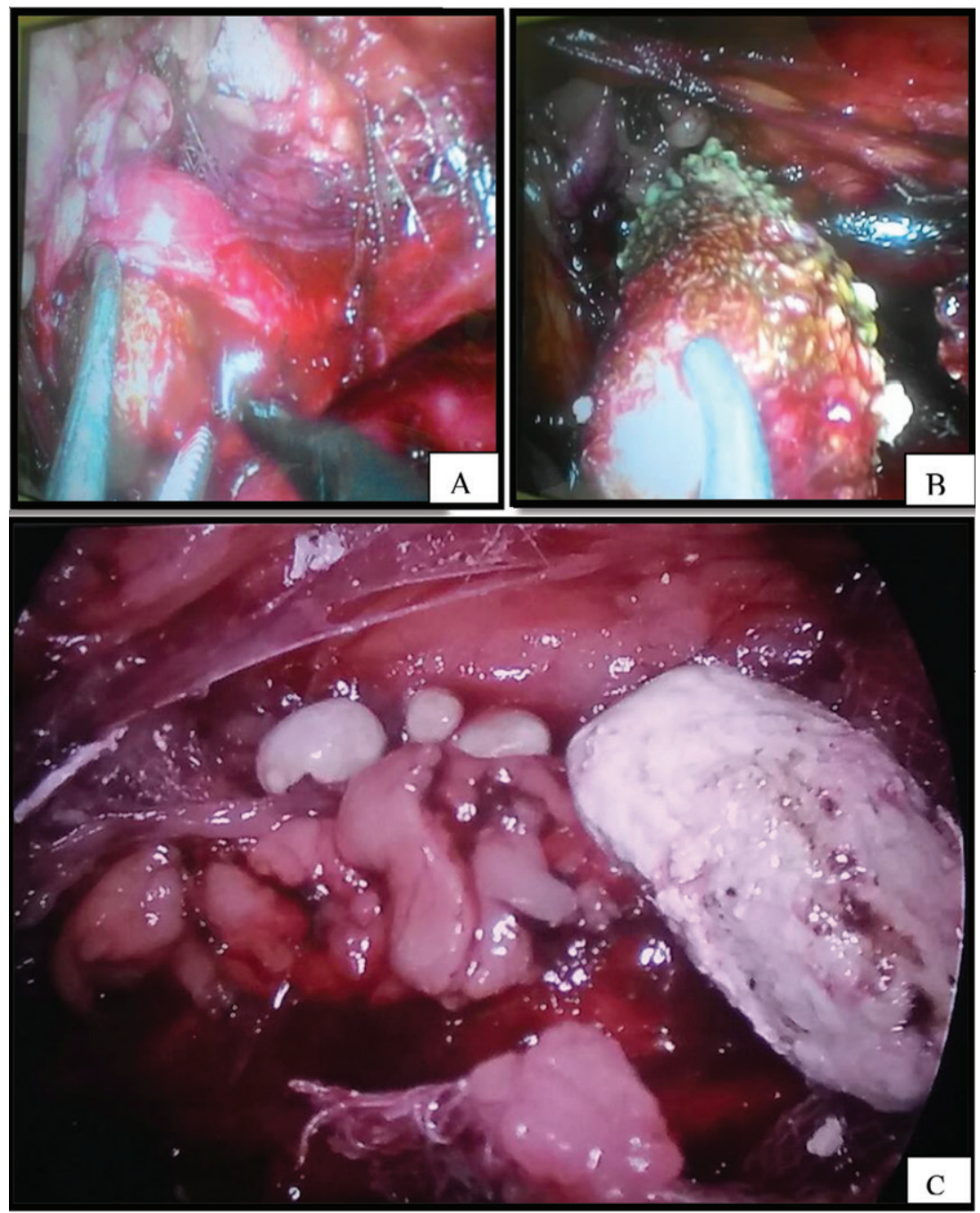

Figure 3. The panoramic view of Laparoscopic Pyelolithotomy
Brandan A. Kramer et al. reported five patients underwent laparoscopic pyelolithotomy with no minor and major surgery complications, and the estimated blood loss was $<50 \mathrm{~mL}$ in all cases. All patient were discharged on postoperative day 1 with the drains removed. ${ }^{2}$

Volkan et al reported most cases of the stone disease in congenitally abnormal kidneys can be treated laparoscopically with low postoperative morbidity and complication rates, a short convalescence time, and good functional results. ${ }^{4}$

Andrei Nadu et al., Selçuk et al., Chao Qin et al reported that although classical endourological procedures should remain as the gold standard for the great majority of renal stones, however patients with a large stone from a combined laparoscopic and endourological disease and repairs associated anomalies. ${ }^{9-12}$

Yasser et al. reported, there was a statistically significant difference between the groups regarding mean estimated blood loss, mean hospital stay rate, and stone-free rate. The mean operative time was significantly longer in laparoscopic pyelolithotomy than percutaneous nephrolithotomy. Although PNL is the standard treatment in most cases of renal pelvic stones, LPL is another feasible surgical technique for patients with large renal pelvic stones. ${ }^{5}$

Asim Mushtaq Patloo reported there was no statistically significant difference in the postoperative pain scores or analgesia requirements, and postoperative complication was only slightly more frequently in the laparoscopic group than the open group, but the mean hospital stay of the laparoscopic group was shorter than the open group. ${ }^{3}$

Table 2. Post-operative result among patients

\section{Parameters \\ Patient 1 \\ Patient 2 \\ Patient 3 \\ Patient 4 \\ Patient 5 \\ Patient 6 \\ Patient 7}

\begin{tabular}{|c|c|c|c|c|c|c|c|}
\hline $\begin{array}{l}\text { Operative } \\
\text { time(minutes) }\end{array}$ & 150 & 130 & 120 & 110 & 100 & 90 & 90 \\
\hline Bleeding & 50 & 40 & 30 & 30 & 35 & 30 & 30 \\
\hline Drain removal & 2 days & 2 days & 2 days & 2 days & 2 days & 2 days & 6 days \\
\hline $\begin{array}{l}\text { Post-operative } \\
\text { Complication }\end{array}$ & None & None & None & None & None & None & None \\
\hline $\begin{array}{l}\text { Post-operative } \\
\text { Day 1,VAS }\end{array}$ & 1 & 1 & 1 & 2 & 1 & 2 & 2 \\
\hline $\begin{array}{l}\text { Pain } \\
\text { Management }\end{array}$ & Paracetamol & Paracetamol & Paracetamol & Paracetamol & Paracetamol & Paracetamol & Paracetamol \\
\hline $\begin{array}{l}\text { Post-operative } \\
\text { length of stay }\end{array}$ & 3 days & 3 days & 3 days & 3 days & 3 days & 3 days & 7 days \\
\hline
\end{tabular}


Gaurav et al. reported that retroperitoneoscopic pyelolithotomy was associated with longer operating time, more invasive \& less cosmetic, require more analgesia, had more blood loss as compared to percutaneous nephrolithotomy. While patients undergo percutaneous nephrolithotomy had shorter hospital stay \& rapid return to normal activity \& more cost effective as compared to retroperitoneal laparoscopic pyelolithotomy. ${ }^{6}$

Although it is uncommonly performed, laparoscopic pyelolithotomy can be a useful treatment for renal calculi not a meanable to more common surgical techniques. In particular, the technique can be beneficial in patients who are having a poorly compliant, renal anomalies, and have a large single renal-pelvic calculus. ${ }^{1-9}$

Even though results of retroperitoneal laparoscopic pyelolithotomy in managing extrarenal pelvic stone disease in our initial experience seems satisfactory, longer follow-up and more cases are necessary to better elucidate the exact role of laparoscopy in today's management of stone disease.

\section{CONCLUSION}

Retroperitoneal laparoscopic pyelolithotomy is a safe alternative for the management of pelvic renal calculi with minimal post-operative pain and length of stay.

\section{ETHICAL CLEARANCE}

This study has obtained ethical approval from the Ethics Committee of Udayana University prior study begun.

\section{CONFLICT OF INTEREST}

No competing interest regarding manuscript

\section{FUNDING}

The authors are responsible for the study funding without involvement any scholarship, grant, or any other resources of funding

\section{REFERENCES}

1. Tiselius HG, Ackermann D, Alken P, Buck C, Conort $\mathrm{P}$, Gallucci $\mathrm{M}$ et al. Guidelines on urolithiasis. Eur Urol. 2001; 40(4):362-71.

2. Kramer BA, Hammond L, Schwartz BF. Laparoscopic pyelolithotomy: indications and technique. J Endourol. 2007; 21(8):860-1.

3. Patloo AM, Sarmast AH, Khan MA, Khan MA, Zaz M, Khan MA et al. Laparoscopic retroperitoneal pyelolithotomy and open pyelolithotomy: a comparative study. Turkish Journal of Urology 2012; 38(4): 195-200.

4. Tuğcu V, Sönmezay E, Yollu V, Polat P, Taşçi AI. Laparoscopic transperitoneal pyelolithotomy as an alternative to percutaneous nephrolithotomy for stones in anomalous kidneys: a preliminary report. Turkish Journal of Urology. 2011;37(3):223-228.

5. Haggag YM, Morsy G, Badr MM, Al Emam AB, Farid M, Etafy M. Comparative study of laparoscopic pyelolithotomy versus percutaneous nephrolithotomy in the management of large renal pelvic stones. Can Urol Assoc J. 2013; 7(3-4):E171-5

6. Agrawal G. The efficacy, safety \& outcomes of laparoscopic pyelolithotomy (retroperitoneoscopic pyelolithotomy) and its comparison with percutaneous nephrolithotomy. International Journal of Biomedical and Advance Research. 2015; 6(04): 363-367.

7. Knoll T. Epidemiology, Pathogenesis, and Pathophysiology of Urolithiasis: European Association of Urology. European Urology Supplements. 2010; 9(12):802-806

8. Hjermstad MJ, Fayers PM, Haugen DF, Caraceni A, Hanks GW, Loge JH et al. Studies comparing Numerical Rating Scales, Verbal Rating Scales, and Visual Analogue Scales for assessment of pain intensity in adults: a systematic literature review. J Pain Symptom Manage. 2011; 41(6):1073-93

9. Nadu A, Schatloff O, Morag R, Ramon J, Winkler H. Laparoscopic surgery for renal stones: is it indicated in the modern endourology era?. Int Braz J Urol. 2009; 35(1):9-17

10. Gandhi KR, Wabale RN. A Rare Presentation of the Extra Renal Pelvis Containing Multiple Calculi; Pravara Med Rev 2015; 7(2):30-32

11. Altın S, Topaktaş R, Akkoç A, AydınC, Girgin R. Our Initial Experiences with Laparoscopic Urologic Surgery. Dicle Medical Journal. 2016; 43 (1): 43-49

12. Qin C, Wang S, Li P, Cao Q, Shao P, Li P et al. Retroperitoneal laparoscopic technique in treatment of complex renal stones: 75 cases. BMC Urol. 2014;14:16

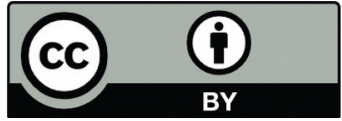

This work is licensed under a Creative Commons Attribution 